\title{
Infants Compensate Energy Intake Fully for Modest Reduction in Energy Density of Formula
}

\section{SJ Fomon, SE Nelson and EE Ziegler*}

Department of Pediatrics, University of Iowa, Iowa City, USA

*Corresponding Author: EE Ziegler, Department of Pediatrics, University of Iowa, Iowa City, USA.
Received: January 15, 2021

Published: February 26, 2021

(C) All rights are reserved by SJ Fomon., et al.

\begin{abstract}
Infants regulate food intake primarily to satisfy energy needs. Feedings with widely different energy densities (e.g., 54 vs 100 $\mathrm{kcal} / 100 \mathrm{ml}$ ) result in different energy intakes in infants $<2$ months old but not later. It is not known how infants handle smaller differences in energy density. We used two milk-based formulas that were practically identical in composition except that one (Formula A) was lower in fat content $(2.70 \mathrm{~g} / 100 \mathrm{~g})$ and energy density ( $60.2 \mathrm{kcal} / 100 \mathrm{~g})$ than the other (Formula B, fat $3.43 \mathrm{~g} / 100 \mathrm{~g}$, 68.9 $\mathrm{kcal} / 100 \mathrm{~g}$ ). The primary study outcome was weight gain, with amount of formula and other foods consumed the secondary outcome. Normal term infants $(\mathrm{N}=76)$ were enrolled before 9 days of age and assigned randomly to one of the formulas, which were fed during the entire study to age 224 days (exclusively until 140 days of age). Of the 61 infants who completed the study and whose data are reported, 31 (14 males, 17 females) were fed A and 30 (16 males, 14 females) were fed B. Weight was measured every 14 days until 56 days and then every 28 days. Food intake was determined by weighing containers. Other foods were permitted after 140 days of age. Results: Between 8 and 224 days of age, infants fed A consumed significantly more formula (155 $\pm 12 \mathrm{~g} / \mathrm{kg} / \mathrm{d})$ than infants fed B $(137 \pm 11 \mathrm{~g} / \mathrm{kg} / \mathrm{d} ; \mathrm{p}<0.001)$. On the other hand, total energy intakes were similar: $94.3 \pm 5.7 \mathrm{kcal} / \mathrm{kg} / \mathrm{d}$ with A and $95.6 \pm 6.4 \mathrm{kcal} /$ $\mathrm{kg} / \mathrm{d}$ with B. Between 8 and 56 days, there was no significant difference in energy intake. Intake of other foods after 140 days was similar. There were no feeding-related differences in anthropometric results. We conclude that infants compensate fully for a modest difference in energy density of formula.
\end{abstract}

Keywords: Feedings; Density; Food Intake

\section{Introduction}

The breastfed infant seems to have the ability to self-regulate the amount of milk consumed, in spite of wide variability of milk composition combined with the mother's inability to determine the amount of milk consumed [1]. This shows that the infant must be able, within limits, to self-regulate the amount of milk consumed in order to meet needs. What we know about this ability of the infant we know from studies where formulas with different ca- loric densities were fed. These studies indicate that infants regulate the volume of intake in order to meet needs for energy.

Studies examining the ability of the infant to regulate the intake of feeds have used formulas with variable caloric density. Thus, when in the study of Fomon., et al. [2] formulas that differed greatly in caloric density (54 vs $100 \mathrm{kcal} / 100 \mathrm{ml}$ ) were fed ad libitum to normal female infants, those infants fed the $54 \mathrm{kcal} / 100 \mathrm{~g}$ formula consumed $201 \mathrm{~g} / \mathrm{kg} / \mathrm{d}$ during the period 8-42 days, whereas infants fed the $100 \mathrm{kcal} / 100 \mathrm{~g}$ formula consumed $126 \mathrm{~g} / \mathrm{kg} /$ day. This 
translated to calorie intakes of $107 \mathrm{kcal} / \mathrm{kg} / \mathrm{d}$ with the low-calorie formula and $126 \mathrm{kcal} / \mathrm{kg} / \mathrm{d}$ with the high-calorie formula. The difference in caloric intake was reflected in a difference in weight gain, which was $29.8 \mathrm{~g} / \mathrm{d}$ with the low-calorie formula compared to 41.9 $\mathrm{g} / \mathrm{d}$ with the high-calorie formula $(\mathrm{p}<0.01)$ However, during the older age interval 42 -112 days, intakes of calories were similar with the two formulas, and accordingly weight gain was similar. Clearly, during the first 42 days of life, infants are not able to make up completely for a two-fold difference in caloric density, whereas infants older than 42 days are able to adjust the volume of formula consumed to make up for this large difference in caloric density. These findings confirmed those reported earlier by Fomon., et al. [3] from comparing formulas with caloric densities of $67 \mathrm{kcal} / 100$ $\mathrm{g}$ and $133 \mathrm{kcal} / 100 \mathrm{~g}$ in normal male infants. Again, infants younger than 42 days were not able to compensate fully for the difference in caloric density, whereas infants aged 42-112 days were able to compensate and did so with remarkable precision.

The present study was undertaken to determine whether the regulatory mechanism is able to recognize and make up for a much smaller difference in caloric density (68 vs $60 \mathrm{kcal} / 100 \mathrm{~g}$ ). The study was also extended to 224 days of age in order to examine if the regulatory mechanism also works when a portion of the intake is provided by other foods besides formula. The primary study outcome was weight gain, with amount of formula and other foods consumed as secondary outcomes.

\section{Methods}

\section{Study design}

This prospective, double-blind, randomized trial was designed to test the hypothesis that growth would be similar but that amount of formula consumed would be different so that energy intake would be similar by infants fed study formulas that differed only in caloric density by a small margin. Full-term male and female infants were enrolled at $8 \pm 2$ days of age and studied to $224 \pm 4$ days of age. At enrollment, infants were assigned randomly with the use of sealed envelopes to one of two formulas (Formula A and Formula B) that were provided in ready-to-feed form in quart cans that were identical in appearance except for the formula code. Infants were fed the assigned study formula ad libitum from 8 through 224 days of age. Parents were requested not to feed complementary foods until after 140 days. Primary study outcome was weight gain, with weight of formula consumed and energy intake as secondary outcomes.
Sample size: A difference in weight gain of $3 \mathrm{~g} /$ day was deemed relevant in accordance with stipulations used by the U.S. Food and Drug Administration. Therefore, 28 infants per group were needed to detect a difference of $3 \mathrm{~g} /$ day with power of 0.8 and at $\mathrm{p}<0.05$. Allowing for a drop-out rate of 25\%, 76 infants needed to be enrolled.

\section{Subjects}

Infants born at term and considered normal by both their parents and by the investigators were enrolled at $8 \pm 2$ days of age. Of 76 infants enrolled, 61 (31 females and 30 males) completed the study as planned and only their data were utilized. Infants were born between April 6, 1992 and June 22, 1993. Reasons for dropping out were mostly technical in nature (family moving away; inability to keep appointments; missed appointments). Infants were similar in birth weight (Table 1) and socio-demographic characteristics (not shown). The study protocol was approved by the University of Iowa Committee on Research Involving Human Subjects and one or both parents gave informed written consent.

\begin{tabular}{|l|c|c|c|}
\hline \multirow{3}{*}{ Birth } & Males & $\begin{array}{c}3536 \pm 470 \\
(\mathrm{n}=14)^{*}\end{array}$ & $\begin{array}{c}3494 \pm 381 \\
(\mathrm{n}+16) \\
\end{array}$ \\
& Females & $\begin{array}{c}3429 \pm 415 \\
(\mathrm{n}=17)\end{array}$ & $\begin{array}{c}3348 \pm 572 \\
(\mathrm{n}=14)\end{array}$ \\
\hline \multirow{2}{*}{112 days } & Males & $6841 \pm 662$ & $6978 \pm 680$ \\
& Females & $6323 \pm 660$ & $6395 \pm 499$ \\
\hline \multirow{2}{*}{224 days } & Males & $8735 \pm 912$ & $8992 \pm 721$ \\
& Females & $8352 \pm 933$ & $8233 \pm 919$ \\
\hline
\end{tabular}

Table 1: Infant weight (g, means \pm SD).

* number of subjects who completed the study.

\section{Study feedings}

Two formulas were used that were nearly identical in composition except that one (Formula A) had a lower fat content than the other (Formula B) (Table 2). The difference in fat concentration explained a difference in caloric density of about $8 \mathrm{kcal} / 100 \mathrm{~g}$. Protein was provided by whey-predominant bovine milk proteins and carbohydrate by lactose. The formulas were prepared specifically for the study and were made available in ready-to-feed form in quart cans. 


\begin{tabular}{|l|c|c|}
\hline & Formula A & Formula B \\
\hline Protein (g) & 14.3 & 14.6 \\
\hline Lactose (g) & 73.4 & 74.8 \\
\hline Fat ${ }^{*}$ (g) & 27.8 & 35.8 \\
\hline Energy (kcal) & & \\
\hline Calculated & 601 & 680 \\
\hline Bomb calorimetry & 602 & 690 \\
\hline Calcium (mg) & 683 & 763 \\
\hline Phosphorus (mg) & 419 & 462 \\
\hline
\end{tabular}

Data analysis

Data analysis included descriptive statistics and general linear models analysis. Repeated-measures and cross-sectional analyses, taking into account infant sex, were performed. For the purpose of comparison, reference data from prior studies using identical techniques and involving 340 female and 380 male infants fed formulas with standard caloric density are included [3].

\section{Results}

\section{Amount of food consumed}

Data on weight of food consumed are summarized in table 3.

Table 2: Nutrient composition of study formulas (per $1000 \mathrm{~g}$ ).

* Blend of high-oleic safflower oil, soy and coconut oils and egg phospholipids.

After age 140 days, parents were free to purchase and feed commercially available baby foods (no beverages) of one manufacturer. In the cases where this was done, we collected the empty containers and weighed them. From the weight of food consumed and the label information, we calculated calories consumed and added them to those consumed from formula.

\section{Study procedures}

Infants visited the Lora N. Thomas Infant Metabolic Unit before 9 days of age, within 2 days of ages 14, 28, 42 and 56 days, and within 4 days of ages 84,112, 140, 168, 196 and 224 days. At each visit body weight and length in the nude state were measured using standard techniques. At some visits samples of capillary blood were obtained (data not shown).

A supply of formula sufficient for 7 days was weighed and delivered to the family. When a new supply was delivered 7 days later, the cans from the previous supply, including full, empty and partially empty cans, were collected and again weighed. The difference in weight was taken as the weight of formula consumed. Commercially prepared complementary foods were purchased after 140 days of age by the parents and empty containers were collected by us and weighed for determination of amount consumed. Energy intake was calculated from the weight of formula and complementary foods consumed and their respective energy density. For formulas the calculated energy density was used. Protein intake was determined in similar fashion (data not shown). Personnel involved in the study were blinded as to the caloric density of formulas.

Food consumption (g/kg/day) was higher by infants fed Formula A in all age intervals and both genders. The difference was statistically significant in all age intervals, except in females between 8 and 56 days of age. Intakes by males tended to be slightly higher than those by females. Intakes by infants fed Formula B were similar to intakes by the reference infants. Overall, food intake by infants fed Formula A was higher than that by infants fed Formula B.

\begin{tabular}{|l|c|c|c|c|}
\hline $\begin{array}{c}\text { Age } \\
\text { interval } \\
\text { (days) }\end{array}$ & Formula A & $\begin{array}{c}\text { p- } \\
\text { value }\end{array}$ & Formula B & Reference \\
\hline Females & $(\mathrm{N}=17)$ & & $(\mathrm{N}=14)$ & $(\mathrm{N}=340)$ \\
\hline $8-56 \mathrm{~d}$ & $184 \pm 16$ & $\mathrm{NS}$ & $175 \pm 26$ & $175 \pm 20$ \\
\hline $56-112 \mathrm{~d}$ & $165 \pm 15$ & 0.003 & $147 \pm 16$ & $150 \pm 14$ \\
\hline $8-112 \mathrm{~d}$ & $174 \pm 12$ & 0.012 & $160 \pm 19$ & $161 \pm 14$ \\
\hline $\begin{array}{l}112-224 \\
\mathrm{~d}\end{array}$ & $145 \pm 10$ & 0.002 & $132 \pm 10$ & -- \\
\hline $8-224 \mathrm{~d}$ & $159 \pm 9$ & 0.001 & $145 \pm 12$ & -- \\
\hline Males & $(\mathrm{N}=14)$ & & $(\mathrm{N}=16)$ & $(\mathrm{N}=380)$ \\
\hline $8-56 \mathrm{~d}$ & $193 \pm 16$ & 0.004 & $171 \pm 19$ & $177 \pm 19$ \\
\hline $56-112 \mathrm{~d}$ & $171 \pm 20$ & 0.001 & $144 \pm 13$ & $148 \pm 13$ \\
\hline $8-112$ & $181 \pm 13$ & 0.001 & $157 \pm 14$ & $161 \pm 13$ \\
\hline $112-224$ & $147 \pm 12$ & 0.004 & $134 \pm 15$ & -- \\
\hline $8-224$ & $163 \pm 12$ & 0.001 & $145 \pm 9$ & -- \\
\hline
\end{tabular}

Table 3: Food intake* (g/kg/d; means \pm SD).

* Intake of formula plus, after 140 days of age, intake of other foods.

Energy intake

Table 4 summarizes data on energy intake. It is evident that energy intakes were very similar by infants fed Formula A and 
Formula B, and that intakes of both groups were similar to intakes by the reference group. None of the differences in mean values were greater than $5 \mathrm{kcal} / \mathrm{kg} / \mathrm{d}$, with the exception of the difference among females from 8 to 56 days of age, where average intake by infants fed Formula A was $8 \mathrm{kcal} / \mathrm{kg} / \mathrm{d}$ lower than that by infants fed Formula B, and $6 \mathrm{kcal} / \mathrm{kg} / \mathrm{d}$ lower than intake by the reference group. Neither of these differences, nor any other differences, were statistically significant. Overall, energy intakes by infants fed the two formulas did not differ significantly.

\begin{tabular}{|c|c|c|c|}
\hline \multicolumn{4}{|c|}{ Females } \\
\hline Age Interval & Formula A & Formula B & Reference \\
\hline & $(\mathrm{N}=17)$ & $(N=14)$ & $(N=340)$ \\
\hline $8-56 d$ & $108 \pm 10$ & $116 \pm 17$ & $114 \pm 13$ \\
\hline $56-112 d$ & $96 \pm 9$ & $97 \pm 11$ & $98 \pm 9$ \\
\hline $8-112 d$ & $101 \pm 7$ & $106 \pm 13$ & $105 \pm 9$ \\
\hline $112-224 d$ & $85 \pm 6$ & $87 \pm 6$ & -- \\
\hline $8-224 d$ & $93 \pm 5$ & $96 \pm 7$ & -- \\
\hline \multicolumn{4}{|c|}{ Males } \\
\hline Age Interval & Formula A & Formula B & Reference \\
\hline & $(N=14)$ & $(N=16)$ & $(N=380)$ \\
\hline $8-56 d$ & $112 \pm 9$ & $113 \pm 13$ & $116 \pm 13$ \\
\hline $56-112 d$ & $100 \pm 12$ & $95 \pm 8$ & $98 \pm 9$ \\
\hline $8-112 d$ & $106 \pm 8$ & $103 \pm 9$ & $106 \pm 9$ \\
\hline $112-224 d$ & $86 \pm 6$ & $88 \pm 9$ & -- \\
\hline $8-224 d$ & $95 \pm 6$ & $95 \pm 6$ & -- \\
\hline
\end{tabular}

Table 4: Energy Intake (kcal/kg/d, means \pm SD).

\section{Weight gain}

Table 5 shows weight gain for the various age intervals. The differences between Formulas A and B were generally small. However, between 8 and 56 days the difference among females was 2.8 $\mathrm{g} / \mathrm{d}$ and among males $3.3 \mathrm{~g} / \mathrm{d}$. Although none of these differences reached statistical significance, the differences are not exactly trivial. They suggest that the mechanism regulating food intake, or the capacity to adjust volume of intake, have not quite reached maturity. Differences in weight gain between infants fed Formulas A and $B$ on the one hand and the reference group on the other hand were very small and not in the same direction. The same was true of differences in length gain and differences in skinfold thick ness (data not shown).

\begin{tabular}{|c|c|c|c|}
\hline \multicolumn{4}{|c|}{ Females } \\
\hline Age Interval & Formula A & Formula B & Reference \\
\hline & $(\mathrm{N}=17)$ & $(\mathrm{N}=14)$ & $(\mathrm{N}=340)$ \\
\hline $8-56 d$ & $32.3 \pm 6.6$ & $35.1 \pm 7.7$ & $32.1 \pm 6.5$ \\
\hline $56-112 d$ & $23.9 \pm 4.4$ & $24.2 \pm 5.2$ & $23.6 \pm 5.4$ \\
\hline $8-112 d$ & $27.8 \pm 4.1$ & $29.2 \pm 6.0$ & $27.5 \pm 4.9$ \\
\hline $112-224 \mathrm{~d}$ & $18.1 \pm 3.3$ & $16.4 \pm 4.9$ & -- \\
\hline $8-224 d$ & $22.8 \pm 3.2$ & $22.6 \pm 5.2$ & -- \\
\hline \multicolumn{4}{|c|}{ Males } \\
\hline \multirow[t]{2}{*}{ Age Interval } & Formula A & Formula B & Reference \\
\hline & $(N=14)$ & $(N=16)$ & $(N=380)$ \\
\hline $8-56 d$ & $36.1 \pm 8.9$ & $39.4 \pm 8.1$ & $38.3 \pm 7.0$ \\
\hline $56-112 d$ & $27.5 \pm 5.9$ & $27.4 \pm 6.6$ & $26.9 \pm 6.6$ \\
\hline $8-112 d$ & $31.4 \pm 5.2$ & $33.0 \pm 6.9$ & $32.2 \pm 5.6$ \\
\hline $112-224 \mathrm{~d}$ & $16.9 \pm 3.5$ & $18.0 \pm 2.7$ & -- \\
\hline $8-224 d$ & $23.9 \pm 3.8$ & $25.2 \pm 3.9$ & -- \\
\hline
\end{tabular}

Table 5: Weight Gain (g/d, means \pm SD).

\section{Discussion}

The ability of the breastfed infant to obtain the amount of milk needed for growth and well-being is essential for survival Neville [1]. From what little is known about the regulatory mechanisms involved, it has been concluded that the infant regulates intake primarily to satisfy caloric needs. The caloric density of breast milk changes dramatically during each feeding session. It also differs between morning and evening and between left and right breast. The breastfeeding mother is not aware of these changes and is not able of estimate the volume of milk the infant consumes [5]. Despite these limitations, the infant obtains the amount of milk he/ she needs in order to thrive. This ability shows that the infant must possess well-functioning mechanisms that enable him/her to consume exactly the amount of milk needed.

In two prior studies from this unit (Fomon., et al. [1,2]) it was shown that even two-fold differences in caloric density are fully compensated by normal infants older than 42 days. What is new in the present study is that it shows full compensation for very small differences in caloric density, and that the mechanism is nearly fully developed in the infant younger than 56 days. On the other hand, in a study in which skim milk (36 kcal/100 g) was compared to a regular formula in infants aged 112 to 167 days, it was found that in- 
fants were not fully compensating for the large difference in caloric density [6]. The reason for this inability is not clear. It could be that the caloric density of $36 \mathrm{kcal} / 100 \mathrm{ml}$ was just too low for infants to fully compensate. Another possibility is that the high protein concentration of skim milk (3.56 g/100 g) prevented infants from compensating for the difference in caloric density. Which raises the question of whether the regulatory mechanism can be overruled by factors other than caloric density? Infants are known to respond to sweet taste in the short run. In the study by Nisbett and Gurwitz [7] a formula in which two-thirds of the lactose was replaced by the more sweet-tasting sucrose, infants consumed significantly more of the sweeter tasting formula than of the all-lactose formula. Also, Fomon., et al. [8] fed to normal female infants between 8 and 112 days of age formulas that contained as the carbohydrate either sucrose or a bland tasting corn starch hydrolysate in a cross-over design. When infants received the sucrose-containing formula, they consumed significantly greater amounts of calories than during intervals when they received the hydrolysate-containing formula. Despite these differences, overall weight gain was not significantly different. These studies demonstrate that the calorie regulatory mechanism can be overruled by taste. On the other hand, salty taste did not seem to do what sucrose did, as shown by Fomon., et al. [9] in a study comparing consumption of salted solid foods with that of unsalted foods and finding no difference in consumption. Similarly, calorie intake was not affected when the ratio of energy supplied by carbohydrate and fat was altered [10], strengthening the view that the afferent limb of the regulatory mechanism is indeed the caloric content of food. It is thus evident that the mechanism regulating calorie intake can be overruled by certain factors, such as sweetness, but not by some other factors.

Thus, although components of the infant's diet other than calories may provide afferent input to the infant, what is known favors energy as the dominant influence. One conclusion is that attempts to limit the energy intake of infants by simply diluting feedings are bound to fail, given the powerful mechanisms that have been demonstrated in the present and in prior studies. The mechanism seems to be functioning for feedings like formula. The nature of the mechanism is not known. The infant may sense the energy density of milk or sense the energy contained in a meal of milk consumed. The infant also may rely on internal satiety signals to adjust overall milk intake to the desired level. It is of course possible that properties other than energy, such as protein content or flavor, also influ- ence the volume of milk consumed. What little is known suggests that milk intake is regulated to achieve the necessary calorie intake.

The present study was undertaken to examine the infant's ability to detect, and adjust intakes for, small differences in caloric density of the feeding. To summarize, although there were some small differences in energy intake (females only) and weight gain (females and males) during the age interval 8 - 56 days, the differences were not statistically significant and also were inconsistent in direction relative to the reference data. We conclude that the mechanism(s) controlling energy intake are already functioning well even in the young infant, but attain their full maturity not until after 56 days of age. After that age, the mechanism seems to function with remarkable precision, allowing only very small differences in caloric intake. Even when, after 140 days of age, other foods provide some of the intake, the regulatory mechanism functions with high precision.

\section{Conclusion}

The present study presents further evidence for the existence of regulatory mechanisms that allow the infant to regulate his/her caloric intake with considerable precision. Nothing is known about the mechanism involved except that it can be overruled by strong sweet taste of the feeding.

\section{Acknowledgement}

The assistance of Ross Laboratories (now Ross Division of Abbott Laboratories) in preparing the study formulas is gratefully acknowledged. The assistance of Dr. A. S. Ryan in securing the experimental formulas is greatly appreciated. Abbott had no influence on the design of the study and had no influence on the preparation of the manuscript.

Fomon designed the study and wrote the initial draft of the manuscript. Ziegler supervised the study and finalized the manuscript. Nelson performed the statistical analysis.

\section{Bibliography}

1. Neville M C. "Anatomy and physiology of lactation". Pediatric Clinics of North America 48 (2001): 13-34.

2. Fomon SJ., et al. "Influence of formula concentration on caloric intake and growth in normal infants". Acta Paediatrica Scandinavica 64 (1975): 172-181. 
3. Fomon SJ., et al. "Relationship between formula concentration and rate of growth of normal infants". Journal of Nutrition 98 (1969): 241-254.

4. Nelson SE., et al. "Gain in weight and length during early infancy”. Early Human Development 19 (1989): 223-239.

5. Neville MC., et al. "Studies in human lactation: milk volume and nutrient composition during weaning and lactogenesis". American Journal of Clinical Nutrition 54 (1991): 81-92.

6. Fomon SJ., et al. "Skim milk in infant feeding". Acta Paediatrica Scandinavica 66 (1977): 17-30.

7. Nisbett RE and Gurwitz SB. "Weight, sex, and the eating behavior of human newborns". Journal of Comparative Physiology 73 (1970): 245-253.

8. Fomon SJ., et al. "Sweetness of diet and food consumption by infants". Proceedings of the Society for Experimental Biology and Medicine 173 (1983): 190-193.

9. Fomon SJ., et al. "Acceptance of unsalted strained foods by normal infants". Journal of Pediatrics 76 (1970): 242-246.

10. Fomon SJ., et al. "Influence of fat and carbohydrate content of diet on food intake and growth of male infants". Acta Paediatrica Scandinavica 65 (1976): 136-144.

\section{Assets from publication with us}

- Prompt Acknowledgement after receiving the article

- Thorough Double blinded peer review

- Rapid Publication

- Issue of Publication Certificate

- High visibility of your Published work

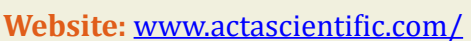
Submit Article: www.actascientific.com/submission.php Email us: editor@actascientific.com

Contact us: +919182824667

Citation: SJ Fomon., et al. "Infants Compensate Energy Intake Fully for Modest Reduction in Energy Density of Formula". Acta Scientific Nutritional Health 5.2 (2021): 37-42. 